\title{
Ensino superior e desenvolvimento regional: o Norte de Minas Gerais na década de 1960
}

\author{
CÉSAR ROTA JÚNIOR \\ Faculdades Integradas Pitágoras de Montes Claros, \\ Montes Claros, MG, Brasil
}

MARIA HELENA DE SOUZA IDE Universidade Estadual de Montes Claros, Montes Claros, MG, Brasil

\section{RESUMO}

O processo de implantação do ensino superior na região norte do estado de Minas Gerais, na década de 1960, ocorreu duas ou três décadas depois de sua efetivação em outros pontos do estado. Nesse período, os discursos sobre a região oscilavam entre seu grande potencial de desenvolvimento e uma marca de atraso econômico e social. Assim, por meio de pesquisa, buscou-se investigar os condicionantes históricos, com base em documentos oficiais e da imprensa escrita, que contribuíram para a concretização do ensino superior no Norte de Minas. Pode-se concluir que o desencadeamento do processo de desenvolvimento econômico regional, impulsionado por ações do Estado, veio a exigir maior investimento em educação, a fim de formar cidadãos que pudessem dar sua contribuição ao processo de industrialização e adaptados à consequente urbanização, culminando no estabelecimento dos primeiros cursos superiores, todos de formação de professores.

\section{PALAVRAS-CHAVE}

ensino superior; pesquisa histórica; Norte de Minas Gerais; desenvolvimento regional. 


\section{HIGHER EDUCATION AND REGIONAL DEVELOPMENT: THE NORTH OF MINAS GERAIS IN THE 1960s}

\section{ABSTRACT}

The process of establishing higher education in the northern region of the state of Minas Gerais in the 1960s, occurred two or three decades after its establishment in other regions of the state. During this period, the discourses on the region ranged from its great potential for development to a mark of social and economic backwardness. Thus, through historical research, we sought to investigate the historical conditions, based on the analysis of official documents and the written press, which contributed to the implementation of higher education in the North of Minas Gerais. It was possible to conclude that the onset of the process of regional economic development, impelled by state actions in order to form citizens who could make a contribution to the process of industrialization and be adapted to the consequent urbanization, culminated in the establishment of the first university courses, which were all for the training of teachers.

\section{KEYWORDS}

higher education; historical research; Northern of Minas Gerais; regional development.

\section{EDUCACIÓN SUPERIOR Y DESARROLLO REGIONAL: EL NORTE DE MINAS GERAIS EN LA DÉCADA DE 1960}

\section{RESUMEN}

El proceso de implantación de la educación superior en la región norte del estado de Minas Gerais, en la década de 1960, ocurrió dos o tres décadas después de su efectuación en otras regiones del estado. En este periodo, los discursos sobre la región oscilaban entre su gran potencial de desarrollo y una marca de atraso económico y social. De este modo, mediante investigación histórica y a partir del análisis de documentos oficiales y de la prensa escrita, se trató de investigar los condicionantes históricos que han contribuido a la concretización de la educación superior en el Norte de Minas Gerais. Se puede concluir que el desencadenamiento del proceso de desarrollo económico regional, impulsado por acciones del Estado, exigió una mayor inversión en educación, con el fin de formar ciudadanos que pudieran contribuir al proceso de industrialización adaptándose a la consiguiente urbanización, culminando en la implantación de los primeros cursos, todos de formación de profesores.

PALABRAS-CLAVE

educación superior; investigación histórica; Norte de Minas Gerais; desarrollo regional. 
O presente texto descreve a implantação do ensino superior no Norte de Minas Gerais, na década de 1960, relacionando-a ao processo de modernização pelo qual começava a passar a região no mesmo período e aos discursos que ligavam, de alguma maneira, o ensino superior ao desenvolvimento regional.

Por meio de pesquisa documental, para a qual foram utilizados como fontes documentos oficiais do estado de Minas Gerais e da prefeitura de Montes Claros, cartas oficiais e imprensa escrita da época, como jornais e revistas, notamos que um número expressivo de documentos referia-se à Faculdade de Filosofia, Ciências e Letras do Norte de Minas (FAFIL), vinculada à Fundação Universidade Norte-Mineira (FUNM). A análise permitiu concluir, embora algumas interrogações perdurem, que tal fato esteve ligado à necessidade de formação de professores de educação básica, objetivando ampliar o sistema público de ensino na região e reduzir os altos índices de analfabetismo.

A ênfase da análise histórica realizada recaiu sobre os discursos produzidos por ocasião dessa implantação, que ocorreu décadas após seu início no restante do estado, com alguns pontos estruturantes relacionados à necessária modernização da região e o lugar da educação nesse processo, bem como sua preparação ao desenvolvimento que se almejava e que começava a se fazer presente. Assim, antes de descrevermos o processo de implantação do ensino superior na região, objeto da pesquisa, optamos por caracterizar o contexto histórico em que esse processo se deu, entendendo-o como fundamental para a análise aqui realizada.

\section{O NORTE DE MINAS NAS DÉCADAS DE 1950 E 1960}

Os discursos sobre a região pareciam oscilar entre seu atraso e seu imenso potencial de desenvolvimento. Os ideais desenvolvimentistas alimentaram de maneira significativa ambas as visões, como bem descreve Anete Pereira (2007, p. 108):

Nessa época, em sintonia com o ideário desenvolvimentista que tomava conta do país, os grupos dirigentes do Norte de Minas articularam-se para atrair à região os recursos estaduais e federais, principalmente para o setor de energia e transportes, bem como a indústria. Essa última, por sua vez, implicaria a inserção definitiva da região no tão sonhado desenvolvimento. Para tanto, houve a preocupação em identificar essa área com as imagens de progresso, urbanidade e "civilização". A cidade de Montes Claros era abordada nos jornais locais como a "Princesa do Norte", o "Coração robusto do sertão".

Para Laurindo Pereira (2007), a região Norte de Minas esteve à margem do desenvolvimentismo dos anos 1950, tendo ocorrido a ação do Estado, de forma efetiva, apenas em meados da década seguinte, principalmente pelos investimentos em energia e transportes e pelos incentivos fiscais criados pela Superintendência do Desenvolvimento do Nordeste (SUDENE). Segundo o autor, para "Montes Claros, o desenvolvimentismo representou uma grande esperança: faltava energia não só para a industrialização como também para consumo doméstico, e as estradas da região eram precaríssimas" (idem, p. 51). Ressaltamos que o eixo norteador do modelo 
de desenvolvimento implementado pela SUDENE na região pautava-se, acima de tudo, no processo de industrialização. Apesar de haver, em seu início, um marcante vetor de equidade regional e social, somente ao longo das décadas de 1970 e 1980 foi possível notar o privilégio dado à expansão industrial e ao desenvolvimento econômico em detrimento de quaisquer ações de cunho social (Oliveira, 1996).

Em artigo publicado no jornal Gazeta do Norte, em 11 de fevereiro de 1960, Gelmires Reis, ao elogiar a construção de Brasília, ligando-a ao início efetivo do progresso do cerrado brasileiro, afirma: "A nossa cidade [...] se vê, de um momento para outro, sacolejada violentamente pelo progresso, sempre desejado, mas somente agora realizado [...]" (Reis, 1960, p. 1).

Até a década de 1950, a maior parte da população da região encontrava-se na zona rural, em atividades agropecuárias e extrativistas, situação que se inverte nas décadas seguintes. Além do processo de urbanização do município, nota-se o aumento da população geral, influenciado pelo processo migratório regional. Faz-se necessário refletir sobre a pressão que tal processo acabou por criar com relação ao acesso à escolarização, bem como, e principalmente, sobre a capacidade de a cidade responder a tal demanda, que, como se verá adiante, era a princípio bastante limitada, sobretudo pela ausência de professores habilitados.

A centralidade da cidade de Montes Claros na região Norte de Minas, apesar de não se configurar como ponto de discussão do presente trabalho, é assunto que merece menção.

a sua posição de centro regional desponta no final do século XIX, mas só se consolida no início do século XX, pois até então Januária e, posteriormente, Pirapora eram os centros mais importantes da região. A centralidade de Montes Claros passou a existir quando ocorreu a instalação de infraestrutura nesta parte do território, principalmente aquelas voltadas à circulação de recursos humanos e materiais, isto é, quando foram construídas estradas interligando-a a diversos municípios e instalou-se nela uma diversidade de serviços. (Pereira, A. M., 2007, p. 90)

Acrescemos que, por meio da pesquisa documental, tivemos acesso a cartas, memorandos e ofícios, em papel timbrado, da Prefeitura Municipal de Montes Claros, documentos estes que na década de 1960 traziam como nota de rodapé os seguintes dizeres: "A cidade que mais cresce na área da SUDENE. Aplique aqui o seu Capital".

Concordamos com a hipótese de Laurindo Pereira (2007) de que o processo de modernização do Norte de Minas se deu sob intensa mobilização da elite política local. $\mathrm{O}$ autor afirma também que a elite política norte-mineira era formada, em sua maior parte, por homens que também possuíam lugar de destaque como empresários, fazendeiros e profissionais liberais. $\mathrm{O}$ trecho a seguir sintetiza essa questão:

Nossa hipótese é a de que, no período que recortamos, os fazendeiros, comerciantes e industriais da região organizaram-se como classe; foram, também, agentes do processo modernizador durante o qual construíram uma ideologia 
regionalista que, compartilhada pelos mais influentes órgãos da sociedade civil, atraindo e agregando intelectuais como jornalistas, burocratas, tecnólogos, escritores e professores, permitiu a evolução de uma simples ação corporativa, nas décadas de 1940 e 1950, para o exercício da hegemonia nas décadas finais do século XX. O regionalismo, aqui entendido como a mobilização de um grupo social junto às instâncias do Estado, expressa uma ideologia, uma concepção de mundo produzida e necessária a uma classe social que, expandida para o conjunto da sociedade, adquire a natureza de um senso comum. (Pereira, L. M., 2007 , p. 10, grifos do original)

A imprensa da época mostra-se como exemplo factual do que foi citado, haja vista (re)produzir esse discurso modernizador tanto na frequência com que reportagens desse cunho eram publicadas como no caráter regionalista que portavam, $\mathrm{o}$ mais das vezes, com forte apelo afetivo. A título de exemplo, citamos a reportagem publicada na primeira edição da revista Montes Claros em Foco, de agosto de 1956, página 12, de autoria de José Monteiro Fonseca: "Incrustada no coração sertanejo, Montes Claros é cidade eminentemente mineira: acolhedora e pacata. Apesar de ter-lhe sido nociva a pecha que lhe imputaram, ela possui um povo laborioso e ordeiro, inteligente e hospitaleiro". $\mathrm{O}$ artigo é finalizado reforçando uma imagem específica do povo da região e enfatizando o potencial para o desenvolvimento:

Montes Claros, [...] se desenvolve, progride, projeta-se no cenário da vida nacional, como centro de irradiação e convergência de uma zona enorme, porém esquecida. Ela estimula e dá o exemplo de tenacidade que faz do sertanejo o homem respeitado por sua honestidade e pelo valor de seu trabalho. (idem, ibidem)

Outro ponto-chave no processo de constituição de Montes Claros como cidade-polo foram as comemorações do seu centenário, em 3 de julho de 1957. Para Laurindo Pereira (2007, p. 53), referindo-se a Hobsbawm (1984), tal ponto se tratou, em verdade, de uma tradição inventada, essencialmente ideológica, tendo sido "uma estratégia cuidadosamente planejada para solidificar as relações políticas de dependência e dominação, construir a imagem de uma cidade moderna, de um povo ordeiro e trabalhador e, por fim, atrair os tão reclamados investimentos do Estado e da União".

A revista Montes Claros em Foco editou um número especial em comemoração ao centenário da cidade, em junho de 1957. Nele, vários artigos escritos por prefeitos e figuras políticas regionais seguem a mesma trilha: um discurso progressista, afirmando Montes Claros como referência de desenvolvimento regional, o que acabaria beneficiando toda a região. ${ }^{1}$

1 Cabe esclarecer que vários são os pontos ligados à ideia de desenvolvimento presentes na imprensa, como a linha de transmissão de energia elétrica de Três Marias, o asfaltamento das estradas da região, várias obras de urbanização da cidade, a instalação de indústrias, o papel da SUDENE tanto na indignação pela exclusão inicial do Polígono das Secas de sua área de abrangência como sua posterior integração, e não somente dos 
Outro ponto importante é a intervenção do Estado na região, relacionando-se ao fomento do desenvolvimento regional, como afirma Oliveira (2000, p. 230):

A partir de 1960, com a intensificação do intervencionismo estatal na Região, este passa paulatinamente a vivenciar novas realidades em vários dos seus aspectos econômicos e sociais. [...] Pois, a partir desta data, teve início um período, de transição, no qual se formalizaram os novos interesses para com a Região norte-mineira; ou seja, tornou-se explícito o papel que esta tenderia a desempenhar no bojo da economia nacional.

O modelo de desenvolvimento das ações estatais nesse período pautava-se, na maioria das vezes, no crescimento econômico, via industrialização e expansão das relações capitalistas de produção na região. Assim, as ações do Estado ali se direcionavam ao crescimento e modernização da economia local, enquanto as atividades que se direcionavam ao ensino escolar restringiam-se à educação primária e secundária, sem nenhuma menção ao ensino superior até então, como demonstra carta enviada em 1959, por via do Ministério da Educação e Cultura (MEC), à Prefeitura Municipal de Montes Claros, em resposta à solicitação de incentivo à implantação do nível superior de ensino na região:

o Conselho de Ministros decidiu que o Governo não deve tomar a iniciativa de criar novos estabelecimentos de ensino superior, pelo menos enquanto não dotar as Universidades e escolas isoladas, atualmente existentes, das condições indispensáveis para o seu regular funcionamento. (MEC, 1959, s.p.)

Destarte, a própria necessidade de expansão, principalmente do ensino secundário, acabou configurando-se como fator decisivo no processo de implantação do ensino superior no Norte de Minas.

\section{O PROBLEMA EDUCACIONAL NO NORTE DE MINAS}

Nesse sentido, alguns aspectos começam a surgir no cenário político da época, como a defesa da industrialização, o investimento em infraestrutura, principalmente energia e transportes, e a defesa da escolarização extensiva a parcelas maiores da população. Nesse quesito, a educação é reconhecida como uma variável a ser considerada essencial à política desenvolvimentista, na trilha da modernização do país, apesar das restrições estatais ao ensino superior no Norte de Minas.

A situação educacional da região era realmente precária. Os Quadros 1 e 2 demonstram as taxas de analfabetismo e o número de escolas e matrículas na cidade de Montes Claros no período em estudo.

problemas educacionais da região. Privilegiamos neste trabalho este último, apenas isso, havendo extensa possibilidade de que outros vieses de análise possam ser executados em outras pesquisas. 
Quadro 1 - Índices de analfabetismo na cidade de Montes Claros, segundo Censo Demográfico de 1950

\begin{tabular}{|c|c|c|c|c|c|c|}
\hline \multirow{3}{*}{\multicolumn{2}{|c|}{ Discriminação }} & \multicolumn{5}{|c|}{ Pessoas presentes, de 5 anos e mais* } \\
\hline & & \multicolumn{3}{|c|}{ Números absolutos } & \multicolumn{2}{|c|}{$\%$ sobre o total } \\
\hline & & Total & Alfabetizados & Não alfabetizados & Alfabetizados & Não alfabetizados \\
\hline \multirow{3}{*}{ Urbano } & Homens & 8.804 & 4.843 & 3.961 & 55,00 & 45,00 \\
\hline & Mulheres & 11.313 & 5.343 & 5.968 & 47,22 & 52,78 \\
\hline & Total & 20.117 & 10.188 & 9.329 & 50,64 & 49,36 \\
\hline \multirow{3}{*}{ Rural } & Homens & 20.098 & 2.783 & 17.315 & 13,84 & 86,16 \\
\hline & Mulheres & 19.227 & 2.113 & 17.114 & 10,98 & 89,02 \\
\hline & Total & 39.325 & 4.896 & 34.429 & 12,45 & 87,55 \\
\hline \multirow{3}{*}{$\begin{array}{l}\text { Em } \\
\text { geral }\end{array}$} & Homens & 28.902 & 7.626 & 21.276 & 26,38 & 73,62 \\
\hline & Mulheres & 30.540 & 7.458 & 23.082 & 24,42 & 75,58 \\
\hline & Total & 59.442 & 15.084 & 44.358 & 25,37 & 74,63 \\
\hline
\end{tabular}

Fonte: IBGE (1959, p. 145).

Elaboração dos autores.

* Optamos por manter o título original da tabela.

Como se pode notar, o índice geral de analfabetismo era de 74,63\%, além de uma importante diferença entre os residentes na zona urbana, 49,36\%, e na zona rural, $87,55 \%$. Cabe acrescer que a "percentagem de alunos matriculados, em relação à população infantil em idade escolar, é de aproximadamente 42,47\%" (IBGE, 1959, p. 145).

\section{Quadro 2 - Números de unidades escolares, professores e matrículas efetivas na cidade de Montes Claros, segundo informações do Serviço de Estatística da Educação do Estado de Minas Gerais}

\begin{tabular}{|l|r|r|r|}
\hline \multirow{2}{*}{\multicolumn{1}{|c|}{ Especificação }} & \multicolumn{3}{c|}{ Dados numéricos } \\
\cline { 2 - 4 } & 1954 & 1955 & 1956 \\
\hline Unidades escolares & 87 & 95 & 78 \\
\hline Corpo docente & 182 & 190 & 176 \\
\hline Matrícula efetiva & 6.136 & 7.616 & 6.738 \\
\hline
\end{tabular}

Fonte: IBGE (1959).

Elaboração dos autores.

Em relação ao Quadro 2, esclarecemos que no ano de 1956 apenas cinco estabelecimentos eram de ensino secundário, sendo todo o restante restrito ao ensino primário (IBGE, 1959). Segundo Maia e Cordeiro (2002), relatando informações obtidas com uma das fundadoras da FUNM, Isabel Rebello de Paula, nos 121 mil $\mathrm{km}^{2}$ da região, com uma população de cerca de um milhão de habitantes, no início da década de 1960 havia apenas 57 estabelecimentos de ensino secundário, sendo que $91,24 \%$ deles eram de iniciativa privada e somente $8,76 \%$ eram públicos. 
Em palestra proferida em 1965 pelo ex-prefeito de Montes Claros Simeão Ribeiro Pires, por ocasião de um curso da Campanha de Aperfeiçoamento e Difusão do Ensino Secundário (CADES) na cidade, encontra-se uma defesa substancial da necessidade de melhoria e expansão do sistema de ensino na região, claramente vinculada ao discurso em prol do desenvolvimento regional:

Ao nosso ver, qualquer processo de desenvolvimento regional só atingirá etapas superiores se tiver a sustentáculo um vigoroso e adequado sistema de ensino. [...] É urgente a necessidade de um sustentáculo educacional para que sejam alcançados níveis satisfatórios de desenvolvimento. Haverá estrangulamento no processo desenvolvimentista quando o sistema educacional é inadequado e frágil. [...] A matriz de nosso atraso é o alto índice de analfabetos, sendo sua rápida redução o primeiro passo para qualquer tentativa de soerguimento regional e nacional. [...] Não constitui novidade para educadores que o rendimento da escola depende da sintonização entre ela e o meio. Onde não existe solicitação material e espontânea, onde as atividades produtivas independem da capacidade de ler e escrever, a resistência à ação da Escola é considerável. [...] É que cumpre, urgentemente, fazer a terra produzir mais, pois é lição eterna, que nunca é demais repetir, mormente agora, para todos os quadrantes do país: - A miséria não deve ser combatida pela simples Distribuição dos que possuem e sim e mais pela Produção dos que são capazes. (Montes Claros em Foco, 1965, s.p., grifos do original)

Notamos, contudo, que a defesa se faz em virtude da ligação que se estabelece entre a educação escolar e o desenvolvimento: a fala denota um sistema educacional consonante com uma perspectiva de desenvolvimento econômico, de modernização da região. $\mathrm{O}$ trecho em destaque deixa claro que a noção de que o desenvolvimento econômico teria como necessária consequência a melhoria das condições de vida da população é a que sustenta a defesa, o que se aproxima muito da perspectiva desenvolvimentista em voga na época.

Em artigo da revista Montes Claros em Foco de 1962, assinado por Otoniel Beleza, a possibilidade da diminuição da desigualdade social é encarada como possível apenas pela caridade cristã, já que a não existência de ações dessa ordem acabariam por abrir espaço ao comunismo. Assim, o discurso reforça a ideia de que ao centro do processo produtivo, ao mercado, só teriam acesso alguns poucos que viessem a se destacar, como se nota no trecho a seguir:

[...] aliviar assim os padecimentos ignorados dos pobres párias da fortuna, dos incapazes para o trabalho, [...] visando não ao nivelamento das classes e condições sociais - coisa absurda e impraticável, como tenho afirmado, - mas à possível redução das diferenças extremas entre umas e outras, no tocante à situação econômica. [...] Assim, estabelecido o equilíbrio dinâmico entre o capital e o trabalho, entre a aristocracia, a mediania e a plebe, pois o problema social é, em última análise, um problema econômico, o povo esquecer-se-á facilmente do credo marxista e jamais precisará dêle, por isso que a caridade cristã, bem compreendida e universalmente praticada, dispensa, como se sabe, todas as pretensiosas inovações de sábios ociosos e ridículos. (Beleza, 1962, p. 32) 
Esses dados, quando cruzados com os discursos de defesa da necessidade da expansão do número de estabelecimentos escolares, corroboram com a tese de Souza (2007, p. 17), quando afirma que, ao se pensar no "movimento da história e as exigências de educação escolar", foi no "século XIX que ela saiu do arbítrio individual e se tornou obrigação pública. Mas, até meados do século XX, bastavam quatro anos de escolarização para alguém ser considerado 'formado' em nível básico".

Isso nos leva a pensar até que ponto o processo de transformação das relações de trabalho na região, principalmente em Montes Claros, tomada como cidade de referência nesse processo de industrialização e incremento do comércio, passou a exigir níveis maiores de escolarização da população, algo que se poderia configurar como um fator de travamento do processo de modernização e desenvolvimento da região. Mas, ao mesmo tempo, pelo viés contrário, não é possível também negar o benefício, em termos mais amplos, que a expansão do sistema de ensino traria à população.

Oliveira (1996), em sua análise do processo de desenvolvimento da região sob a influência da SUDENE, elenca alguns pontos-chave da infraestrutura necessária, a saber: 1) energia; 2) transportes; 3) modernização do setor agrário e pecuário; 4) industrialização; e 5) educação. Neste último ponto, afirma:

Um dos aspectos consensuais sobre o desenvolvimento é que ele não se faz sem melhoria na educação. $\mathrm{O}$ acesso a ela significa uma melhor e maior qualificação de mão de obra. Mais do que isto, representa uma melhoria do padrão de vida, pois este pode ser entendido como uma abertura no campo de escolha do indivíduo. Pois a escolha e a liberdade do indivíduo só podem ser exercidas com um adequado instrumental. (idem, p. 142)

Em contrapartida, apesar da menção à liberdade e possibilidade de escolha, o autor se foca em indicadores de ordem prática e quantitativa, aqueles que, de maneira direta ou indireta, mais interessam ao crescimento econômico, e não ao desenvolvimento do indivíduo e da região de maneira mais ampla. Taxas de analfabetismo e de anos de escolarização da população são exemplos utilizados pelo autor como indicadores de desenvolvimento. A menção à liberdade de escolha é argumento também condizente com uma visão liberal de educação, que contribui com o processo de encobrimento das contradições que lhe são inerentes.

Em termos pedagógicos, ideais de modernização também se fizeram presentes. Retomando os ideais escolanovistas da década de 1930, as reformas educacionais das décadas de 1950/1960 direcionavam-se à capacitação e formação de cidadãos que viessem a compor a mão de obra pronta a dar sua contribuição ao crescimento econômico e ao desenvolvimento (Mendonça et al., 2006). Na região, tais mudanças também engrossavam o discurso da necessidade não só da expansão do sistema de ensino, em todos os seus níveis, inclusive superior, como se pode notar na afirmação da professora Isabel Rebello de Paula, uma das líderes do movimento de implantação do ensino superior na região, citada por Maia e Cordeiro (2002, p. 53):

O perfil dessa nova escola se resumia na fuga do tradicionalismo pedagógico, da rotina, do livresco e do erudito, males e vícios do ensino da época. Na determinação de diretrizes atualizadas e basicamente de interesse regional, na formação de 
uma ética estudantil e profissional. $\mathrm{Na}$ avaliação constante dos seus resultados e efeitos na comunidade em que se propunha atuar, finalmente, na formação de uma equipe aberta, ampla, direta e objetiva, que perseguisse pacientemente seus objetivos.

Um dos mais importantes argumentos utilizados foi o da necessidade da expansão da rede pública de ensino, principalmente do ensino secundário, em uma clara ligação aos ideais desenvolvimentistas de progresso para a região, e sua retirada da situação de atraso econômico e social. Em reportagem do jornal Gazeta do Norte, encontramos um pouco do otimismo relacionado à expansão da rede de ensino, em específico o ensino secundário de nível comercial e técnico.

Por meio dêles, o jovem recebe uma preparação básica e especializada para o trabalho nos diversos setores em que se desdobra aquela atividade - sem que, por isso, deixe de receber uma formação geral adequada. Os Cursos Técnicos de Comércio formam o profissional e o cidadão. (Gazeta do Norte, $1^{\circ}$ jan. 1960, p. 1 , grifos do original $)^{2}$

O texto citado denota não apenas que a educação traria especialização para o trabalho moderno, mas também uma formação de ordem pessoal, ligada à cidadania, de um novo homem preparado a um novo tempo. Aproxima-se muito da noção que Cunha (1985) possui da relação, no período aqui analisado, entre a escolarização e o desenvolvimento, a saber, a de perceber a primeira como mecanismo de transformação dos talentos inatos, individuais, em habilitações cambiáveis, essenciais à chegada ao segundo.

Como na supracitada reportagem, o autor é bastante enfático ao afirmar o papel do ensino de nível médio e técnico como mecanismo de resolução de problemas econômicos e sociais, como o desemprego, no sentido em que este deixa de ser fruto de mecanismos impessoais, macrossociais, e passa a ocupar o lugar da falta de qualificação profissional, da carência de indivíduos ao alcance de um patamar mais elevado de desenvolvimento (idem).

Parece haver, nesse quesito, certa distância histórica entre o Norte de Minas e o restante do estado. $\mathrm{O}$ auge das discussões acerca do ensino técnico-profissionalizante, mesmo que voltadas à modernização do campo, que se deu no início do século XX, ainda na República Velha, somente chega à região em meados do século, também em relação ao campo, mas já principalmente para o incremento da indústria e do comércio (Dulci, 1999).

Assim, em relação à modernização da agricultura, que no período ainda se baseava em uma direção pouco comercial e mais de subsistência, reportagem publicada na cidade argumentava em favor de uma ligação necessária entre aquela e a ampliação do sistema de ensino, via implantação da Escola Média de Agricultura D. José Alves Trindade. Em tal reportagem afirma-se ser louvável qualquer iniciativa, oficial ou privada, de "elevar o índice de instrução e cultura de nossa gente"

2 Optamos, nas citações diretas, por manter a grafia original das palavras. 
(Gazeta do Norte, 7 jan. 1960, p. 1). Segue afirmando o caráter obsoleto da produção agrícola regional, sendo urgente a necessidade de levar "aos agricultores instrução e, principalmente, os conhecimentos técnicos de que carecem" (idem, ibidem). Finaliza o artigo afirmando que "Ao grande povo de Montes Claros um prêmio à sua capacidade e um incentivo à concretização de um futuro de glórias" (idem, ibidem).

Outro ponto importante em relação à modernização da agricultura é a criação, pela lei n. 4.323, de 11 de abril de 1964, do Colégio Agrícola "Antonio Versiani Athayde", tendo sido este incorporado à Universidade Federal de Minas Gerais em 1968, para a formação de técnicos em agropecuária. Em 1975, o colégio é transformado em Núcleo de Tecnologia em Ciências Agrárias, passando a oferecer cursos superiores de curta duração em bovinocultura e administração rural. A questão da modernização do campo é, portanto, ponto-chave no processo de compreensão dos condicionantes da implantação do ensino superior norte-mineiro.

\section{O ENSINO SUPERIOR NORTE-MINEIRO: A FUNDAÇÃO UNIVERSIDADE NORTE-MINEIRA (FUNM)}

O processo de implantação do ensino superior na região centralizou-se em Montes Claros, que, como já visto, havia-se firmado enquanto centro urbano de referência na região, a "capital do Norte de Minas" (Montes Claros em Foco, 1957). Assim, um dos pontos principais da implantação do ensino superior na região parece ter sido a necessidade da expansão do sistema público de ensino, em especial de nível secundário. Há registro, na lei de criação da FUNM, em seu artigo $9^{\circ}$, que os primeiros cursos a serem implantados seriam os de agronomia e veterinária, em virtude da "vocação" da região, no intuito da modernização do setor, direcionando-se à produção comercial. ${ }^{3}$ Apesar disso, os primeiros cursos implantados no início do ano de 1962 foram os de pedagogia, letras, história e geografia, pela maior disponibilidade imediata do corpo docente ${ }^{4} \mathrm{e}$ em virtude da necessidade da expansão do ensino secundário que, como visto, era extremamente escasso na região, impossibilitando o próprio acesso ao ensino superior.

Em artigo publicado no Gazeta do Norte, em 6 de março de 1960, começa a surgir uma ligação da expansão do ensino secundário com o ensino de nível superior, no intuito da necessária continuidade do processo de escolarização da população.

Montes Claros irrefutavelmente vem progredindo em todos os aspectos. Culturalmente o surto de seu desenvolvimento tem sido notável. Diversos novos grupos escolares têm sido ultimamente instalados, na sede do município e elevado também o número de escolas rurais, para as quais foram escolhidas através do curso de suficiência realizado no ano passado, professoras competentes. [...]

3 Adiante discutiremos as intenções e os argumentos relacionados à implantação desses cursos na região.

4 Relatório e Prestação de Contas da Diretoria Executiva da Fundação Educacional Luiz de Paula para a eleição da primeira diretoria da FAFIL, datada de 9 de janeiro de 1964. 
Uma das maiores conquistas no terreno cultural, deve-se apontar a instalação do curso científico anexo à Escola Normal do Estado, facilitando aos menos favorecidos pela fortuna. Estamos informados que o referido curso obedecerá a uma austeridade imprescindível ao melhor aproveitamento do aluno, que, assim, ficará capacitado a enfrentar os exames vestibulares com maior possibilidade de êxito. (Gazeta do Norte, 1960, p. 1, grifos nossos)

Anteriormente à implantação dos referidos cursos superiores, houve em Montes Claros um ciclo de palestras e cursos que tinham por objetivo capacitar e habilitar o professorado a lecionar no ensino secundário. Tais cursos eram vinculados à CADES, de âmbito federal, criada em 1954 e que chegava à cidade em 1960 "com a finalidade de incrementar e dar assistência técnica ao ensino secundário" (Raia, 1960, p. 1). Também concedia "subvenções e bolsas de estudos às Faculdades de Filosofia que instalaram cursos especiais, assim como a candidatos que se disponham a frequentar tais cursos e assumam o compromisso de exercer a função de orientador educacional" (idem, ibidem). Finalizando, o autor do artigo, o professor Antonio Raia, orientador dos cursos da CADES em Monte Claros, afirma que "a ação dêste importante órgão se faz sentir em todos os setores da vida educacional de nossa escola de grau médio, no sentido de dinamizá-la e torná-la mais equânime e ajustada não só à realidade nacional, como também atualizada com a moderna pedagogia" (idem, ibidem). Os chamados "cursos de suficiência" tinham por objetivo "ministrar aos mesmos [professores] noções de didática geral e especial de cada disciplina do currículo secundário, bem como atualizá-los no conteúdo dessas matérias" (idem, ibidem).

Na mesma edição, a professora Yvonne de Oliveira Silveira (1960, p. 3) afirma que os cursos facilitavam "a freqüência para muitos professores que, por diversos motivos, não podem ir para a capital ou outros centros afastados”. Afirma ser uma oportunidade ímpar para que os professores não diplomados nas faculdades de filosofia consigam se preparar para os exames para docência no ensino secundário. "Enquanto as Faculdades de Filosofia não diplomam número suficiente de professores para os estabelecimentos do interior do País, ginásios e colégios são criados sob orientação e fiscalização seguras com professôres capazes de cumprir a elevada missão de ensinar" (idem, ibidem).

De acordo com o Decreto que a criou, para a consecução de seus objetivos, a CADES deveria, entre outras atividades: promover a realização de cursos e estágios de especialização e aperfeiçoamento para professores, técnicos e diretores de estabelecimentos de ensino secundário; conceder e incentivar a concessão de bolsas de estudo a professores secundários, a fim de realizarem cursos ou estágios de especialização e aperfeiçoamento no País ou no exterior; promover estudos dos programas do curso secundário e dos métodos de ensino, a fim de ajustá-los aos interesses dos alunos e às condições e exigências do meio; elaborar material didático para as escolas secundárias; organizar missões culturais, técnicas e pedagógicas para dar assistência e estabelecimentos distantes dos grandes centros; incentivar a criação e o desenvolvimento dos serviços de orientação educacional nas escolas de ensino secundário; divulgar atos e 
experiências de interesse do ensino secundário; e promover o intercâmbio entre escolas e educadores nacionais e estrangeiros. (Pinto, 2000, p. 5)

Segundo a mesma autora, a CADES representou, para a educação brasileira, uma proposta que, ao mesmo tempo em que proporcionava ações pedagógicas e técnicas modernas, foi socialmente conservadora, já que não alterou o caráter elitista e seletivo do ensino secundário no período, o que a enquadra, como discutido anteriormente, como parte de um processo de modernização conservadora (idem), o que viria também marcar o processo de implantação do ensino superior regional.

Para Pinto (2000, p. 2), nesse período, "a ciência e a formação de recursos humanos são valorizados como fatores de progresso e elementos fundamentais para o aprimoramento das forças produtivas e para a expansão do capitalismo”. Assim, a expansão do sistema de ensino também fez parte das ações do Estado que buscavam direcionar o país a outro patamar de desenvolvimento econômico, ações essas

[...] que sintetizavam os componentes essenciais do sistema político-econômico brasileiro da época - nacionalismo econômico, emancipação do País, ideologia desenvolvimentista, incremento da função econômica do Estado - [que] indicavam que o Brasil tinha pressa em se modernizar. (idem, ibidem)

Com esse panorama histórico, em 1960, iniciou-se um movimento para a implantação de uma unidade de ensino superior na região. Segundo Maia e Cordeiro (2002), um grupo de professoras recém-formadas pela Universidade de Minas Gerais, ${ }^{5}$ composto por Isabel Rebello de Paula, Maria Isabel Figueiredo Sobreira, Maria da Consolação de Magalhães Figueiredo, Maria Florinda Pires Ramos e Maria Dalva Dias de Paulo, deu início a um movimento em prol do ensino superior regional. Essas professoras, ainda segundo Maia e Cordeiro ( $\mathrm{idem}$ ), buscaram apoio em autoridades regionais e na comunidade local, proferindo palestras sobre a situação do ensino na região, ancorando-se, o mais das vezes, na necessidade da implantação do ensino superior para formar professores para a expansão do ensino secundário. $\mathrm{O}$ maior intuito das professoras era a formação de uma faculdade de filosofia, ciências e letras, em um direcionamento explícito à formação de professores necessária à ampliação do ensino público regional, principalmente de nível secundário.

A idéia surgiu em 1960. Éramos um grupo pequeno de estudantes bairristas. Em BH, orientadas pelo Prof. Tabajara Pedroso, se lançaram a implantar neste sertão a primeira célula de ensino superior. Durante as férias escolares, a idéia tomou corpo e iniciado o ano letivo de 1961, já nos reuníamos em Belo Horizonte formando equipes de trabalho para levantamento de viabilidade. Só uma coisa era certa: íamos fundar a escola. Como não sabíamos ainda, mas

5 Apesar de ter sido federalizada em 1949, o nome Universidade Federal de Minas Gerais somente foi implantado em 1965. Disponível em: <https://www.ufmg.br/co nheca/hi_index.shtml>.Acesso em: 28 ago. 2013. 
arregaçamos as mangas e nos lançamos ao trabalho. (Anotações pessoais da professora Isabel Rebello de Paula) ${ }^{6}$

Em edição também de 1964, a revista Montes Claros em Foco traz uma entrevista realizada com duas das fundadoras da FAFIL, Maria Isabel Figueiredo Sobreira e Maria da Consolação de Magalhães Figueiredo.

Acontecimento importante para o Norte de Minas, especialmente para Montes Claros, foi a fundação da Faculdade de Filosofia, modernamente chamada de Educação. Além do ensino curricular de preparação de professores do ensino secundário e superior, trará outros empreendimentos culturais. [...] Mary e Baby Figueiredo, Isabel Rabelo ${ }^{7}$ e Florinda Ramos sonharam com a Faculdade. Encontraram apoio nos colegas: Dalva Dias Santiago, Glacira Mendes, M. de Lourdes Freitas e Antônio Francisco de Oliveira. "A idéia da criação de uma Faculdade de Filosofia, em Montes Claros, nasceu há muito tempo, em Belo Horizonte, entre nós, estudantes montesclarenses, que cursávamos a FAFIL. Obteve desde logo o apoio e o incentivo de professôres ilustres como Tabajara Pedroso e Arthur Versiani Velloso. Mas, de potência a ato, o caminho era longo e pedregoso. E nada disso nos desanimava; ao contrário, as dificuldades impulsionavam-nos à luta, movidas que éramos (e ainda o somos!) pelo idealismo, característica essencial dos jovens. $\mathrm{O}$ sonho é agora realidade. MOC tem a sua faculdade de Educação. Êste ato contribuirá para elevar sensivelmente o nível cultural da cidade. Os benefícios são inúmeros e $\mathrm{M}$. Claros conhecerá o equilíbrio econômico, social e intelectual. Não será mais a cidade rica e inculta do sertão; a educação, base da existência, sobrevivência e desenvolvimento de toda a sociedade, trar-lhe-á novo aspecto, enriquecendo aquilo que o homem tem de eterno: - o espírito". Alegra-nos entrevistar môças bonitas e inteligentes assim como Mary, e que, ainda jovens, começam a lutar pelo progresso da terra natal. (Montes Claros em Foco, 1964, s. p.)

Um grande incentivador da proposta foi o professor Arthur Versiani Velloso, diretor da Faculdade de Filosofia da Universidade de Minas Gerais e irmão do farmacêutico Mário Versiani Velloso, residente em Montes Claros, que esteve na cidade proferindo palestras e participando de reuniões de discussão da proposta de implantação do ensino superior na cidade. Em um desses encontros, realizado no dia 25 de julho de 1962, o referido professor afirma, segundo reportagem da Gazeta do Norte:

A idéia central do Prof. Velloso é que Montes Claros, a par dos admiráveis índices de progresso e riqueza que vem ostentando, apresenta, para constituir-se

6 Documento encontrado no Centro de Pesquisa e Documentação Regional (CEPEDOR/ UNIMONTES). Texto datilografado, sem indicação de data ou página.

7 Trata-se de Isabel Rebello de Paula, que foi escrito erroneamente na revista citada. 
em fecundo núcleo cultural, condições dificilmente encontráveis em outros pontos do país. Inicialmente, foi ressaltada a necessidade de prover devidamente as cátedras vacantes no curso secundário, como providência imprescindível para evitar o êxodo de alunos nesse nível de ensino, que representa considerável ônus para a economia local. [...] Quanto à Universidade propriamente dita, ela se constituiria inicialmente de uma Faculdade de Filosofia, que funcionaria com apenas cinco cursos: Português, Inglês, Matemática e História Natural. A seguir, mediante concurso de elementos de fora e de professores egressos da Faculdade de Filosofia, seriam criadas as faculdades de Veterinária e Agronomia, que são os institutos de verdadeira adequação com as necessidades do meio. (Gazeta do Norte, 29 julho 1962, p. 1, grifos nossos)

Retomando a questão da criação e implantação de cursos superiores de agronomia e veterinária, sustentada pelo discurso da vocação agropecuária regional, cabe maior explanação e análise, haja vista tal fato não haver se concretizado, já que os cursos criados integrados à FUNM nos anos seguintes não possuíam nenhuma relação com o campo. Além da FAFIL, foram implantadas outras quatro faculdades ligadas à FUNM: a Faculdade de Direito (FADIR), a Faculdade de Medicina (FAMED), a Faculdade de Administração e Finanças (FADEC) e a Faculdade de Educação Artística (FACEART).

A FAFIL data, então, de 2 de agosto de 1963, tendo sido mantida pela Fundação Educacional Luiz de Paula (FELP), entidade sem fins lucrativos que havia sido instituída em 1961 com o intuito de criar, instalar e manter estabelecimentos de ensino secundário no Norte de Minas. A FAFIL permaneceu vinculada à FELP até 1965, quando foi incorporada à FUNM, que, criada oficialmente em 24 de maio de 1962, somente iniciou suas atividades em 1964 (Maia; Cordeiro, 2002).

Lembramos que a região sofreu, como visto, uma ação de industrialização vinda de fora, da esfera federal, por via principalmente da SUDENE, e da esfera estadual, por programas como o Superintendência do Desenvolvimento da Área Mineira do Polígono das Secas (SUDEMINAS), por meio de isenções fiscais e incremento das redes de energia e de estradas. Também se faz clara a pressão da elite local em relação à implementação dos "pré-requisitos" ao desenvolvimento regional, como a melhoria do sistema de transportes para escoamento da produção e a melhoria do suprimento de energia elétrica, por exemplo, tendo tais avanços efetivamente ganhado forte incremento na década de 1960.

Em relação ao privilégio dado à implantação da FAFIL, com uma ligação explícita com a necessária formação de professores para o ensino secundário, tal fato se nota, segundo Abreu (1968, p. 205), como tendo feito parte de um processo maior, de nível nacional, embora certamente com peculiaridades regionais.

Evidentemente, quando nas últimas décadas se adensou o processo de desenvolvimento nacional com o consolidar de nossa industrialização, não mais seria possível manterem-se as escolas no velho estilo ornamental de transplantação simbólica, porque já não era mais viável que coubesse a uma pequena elite alegórica a tarefa de representar o papel de país civilizado, fazer sozinha as vezes 
de nação. Esta realmente se formava ao impulso do desenvolvimento, quando começavam a se incorporar camadas populares à vida nacional, quando estratos sociais outrora rigidamente estanques se misturavam e integravam e chegava-se àquele ponto crítico da dialética do desenvolvimento, em que se atinge o limiar da ruptura qualitativa entre o processo formal e o processo real, quando não há mais como deixarem as escolas, que precisam ser eficientes, de incorporarem à sua temática valores atuantes, como os científicos e tecnológicos, e de pensarem e agirem em termos de uma cultura nacional, que verdadeiramente se constitui. De outra sorte, tornar-se-iam elas pontos de estrangulamento insustentáveis em relação às imposições indeclináveis do desenvolvimento brasileiro, incapazes de servirem de instrumento ao suporte e direção do nosso progresso, inaptas a constituírem elementos para estudo e solução de nossos concretíssimos problemas, desqualificadas a integrarem, como instituições reais, a nação real.

Assim, um dos principais problemas relacionados à capacidade de responder à crescente demanda por escolarização na cidade de Montes Claros, principalmente do ensino secundário, era o déficit de professores habilitados. Os cursos da CADES, como visto, cumpriram em parte esse papel, mas de forma ainda incipiente, até pelo seu caráter provisório, ao passo que a implantação de uma faculdade de filosofia viria suprir tal carência de maneira muito mais sustentada e duradoura.

Sobre a questão do déficit de professores habilitados, ainda em 1956, o então inspetor itinerante da Inspetoria Seccional de Belo Horizonte, cujo cargo era o de supervisionar a região norte-mineira, além de também ter sido o fundador do Jornal de Montes Claros e redator do Gazeta do Norte, o professor José Monteiro Fonseca afirmava:

A Lei orgânica do Ensino Secundário, de 1942, traçou os objetivos da escola [...], tendo a principal preocupação em cuidar, senão formar, "a personalidade integral do adolescente, estimulando a consciência patriótica e humanista, proporcionando-lhe a cultura geral, com base para estudos superiores". Presentemente temos em Montes Claros 4 estabelecimentos (Escola Normal, Colégio Imaculada Conceição, Instituto Norte Mineiro de Educação e Colégio Diocesano Nossa Senhora Aparecida), onde se ministra o ensino secundário. Quase 2.000 adolescentes frequentam os referidos educandários e se maior não é o seu número é porque as instalações dos mesmos não comportam superior matrícula. Há acentuada tendência para o aperfeiçoamento dos métodos até então adotados, principalmente por parte dos professores jovens, mais acessíveis à moderna didática, menos ligados à escola tradicionalista, mais entusiastas, mais idealistas [...]. A aquisição dos corpos docentes condígnos tem sido um problema cruciante dos educandários. Não queremos frizar a deficiência do nosso professorado, mas apenas salientar a dificuldade de obtê-lo como ele deve ser para que possa corresponder ao desideratum da Lei Orgânica do Ensino Secundário. [...] Apesar disto, a procura de ensino secundário é tão grande, que já se constitui uma das mais sérias preocupações para os que se interessam pelo 
assunto. Preocupação porque os estabelecimentos não estão em condições de atender aos pedidos de matrícula. [...] quanto ao atual corpo docente secundário de Montes Claros, como disse inicialmente, está melhorando muito. Os cursos de suficiência contribuíram grandemente para a elevação do nível da escola secundária aqui. É notório o progresso feito. Que digam os alunos, que são os melhores observadores. (Fonseca, 1956, p. 35-36)

Apesar da implementação de várias ações modernizadoras, “a Região conservou muitas de suas características tradicionais, especialmente aquelas relacionadas ao Poder local, que demonstrou ser forte o suficiente para resistir ao processo de transformação em curso" (Oliveira, 2000, p. 235). A influência das elites regionais parece ter sido uma constante no processo de desenvolvimento do ensino superior em Minas Gerais.

o papel atribuído à educação mineira também estava restrito aos membros das oligarquias, em contraste com o discurso da intelectualidade da época que viam na educação o único caminho para formar o homem que deveria forjar um país livre do atraso econômico e intelectual. (Abreu, 2006, p. 80)

Laurindo Pereira (2007) demonstrou com clareza o papel das elites e do poder local no processo de modernização da região, dando destaque à Sociedade Rural e à Associação Comercial e Industrial (ACI), apontando-as como duas entidades que concentraram o poder local de forma marcante, principalmente em virtude do caráter polivalente de seus membros:

a trajetória dessas duas entidades, as mais influentes da região, revela que as elites regionais evoluíram de fazendeiros, comerciantes e industriais isolados para se constituírem em uma classe organizada que, além da propriedade dos meios de produção e do controle sobre os postos convencionais do Estado (deputados, prefeitos e vereadores), assumiu a direção da sociedade civil, alargando suas concepções de classe e universalizando-as. (Pereira, L. M., 2007, p. 205-206, grifos do original)

Em edição de 1965, a revista Montes Claros em Foco noticia o início do funcionamento da FADIR, cuja aula inaugural seria proferida pelo então governador do estado, Magalhães Pinto, com o tema "Prosperidade perante o direito", e tece elogios ao fato, considerando o evento "uma das melhores iniciativas já promovidas no nosso meio educacional. Representa, não somente para a cidade mas também para toda a região norte do Estado" (Montes Claros em Foco, 1965, s.p.).

Outro ponto decisivo para a manutenção do caráter elitista citado anteriormente foi a manutenção financeira da FUNM. Até sua estadualização, em 1989, quando transformada em Universidade Estadual de Montes Claros (UNIMONTES), ela se manteve por meio da cobrança de mensalidade dos alunos, de doações de empresários, fazendeiros e comerciantes da cidade e da região. Segundo alguns documentos encontrados, a FUNM sempre teve a maior parte de suas receitas advinda dos recursos 
financeiros dos alunos, o que, durante sua primeira década de funcionamento, era da ordem de 81,98\%, enquanto os convênios com o MEC não atingiam 3\%.

Durante a década de 1960, a maior parte das instituições de ensino superior mineiras lutava pela federalização, e a maioria delas obteve êxito ainda nesse período (Abreu, 2006). Porém a FUNM não ficou absolutamente alheia a esse processo, apesar de sua história recente. Em 1975, sob a coordenação do então reitor, professor João Valle Maurício, uma equipe de professores da instituição construiu um projeto com o intuito de demonstrar a situação da FUNM no que dizia respeito a fatores socioeconômicos, a fim de pleitear também a federalização. Embora a própria história tenha mostrado que tal intento foi frustrado, alguns pontos do projeto acabam servindo como parâmetros a uma melhor compreensão daquele contexto.

Em um dos trechos mais importantes à presente análise, quando da argumentação em favor da importância do ensino superior na região, tem-se:

A sua sobrevivência, numa região agreste e isolada dos grandes centros, deve-se sobretudo ao idealismo de seus componentes, ao espírito empreendedor do sertanejo ousado e destemido, que consegue sobrepujar os obstáculos mais difíceis e desalentadores. [...] Sabemos que: - a educação tem repercussão econômica direta sobre o número e o pessoal qualificado, uma vez que as três quartas partes da produção nacional são devidas à mão de obra cuja produtividade depende muito de instrução; - a sociedade, tanto quanto o indivíduo, utiliza a educação como meio de conservar e desenvolver seus sistemas de valores; - a educação estimula a iniciativa e o espírito de criatividade de uma comunidade, melhora a estrutura do consumo, favorecendo a mobilidade social e econômica; - a educação serve de instrumento de seleção, permitindo a uma comunidade encontrar seus dirigentes, empresários, administradores e técnicos; - a educação não é um setor improdutivo da economia. Ao contrário, devemos considerá-la um investimento essencial ao crescimento econômico. Uma região pode transformar-se de maneira brutal concentrando os recursos disponíveis em educação. [...] Não pode baver politica de desenvolvimento sem uma política educacional; - a educação deixou de ser privilégio de uma elite, tendendo cada vez mais a ser coextensiva em relação à totalidade da comunidade. $(1975, \text { p. } 2 \text {, grifos do original })^{8}$

Nota-se que o discurso se sustenta na noção de que investir em educação é investir no sistema econômico, ligando o sistema de ensino à capacitação e qualificação do trabalhador, e que aquela, por sua vez, além de propiciar o desenvolvimento econômico, propiciaria mobilidade social. Não que tal mobilidade tenha um caráter falacioso, pois, efetivamente, uma melhor colocação no mercado pode, de fato, proporcionar uma maior ou menor melhoria das condições de vida da população, mas o acesso ao ensino superior permaneceu restrito a poucos, assim como o espaço no

8 Documento encontrado no Centro de Pesquisa e Documentação Regional (CEPEDOR/ UNIMONTES). Texto datilografado, sem indicação de data ou página, cujo título é Aspectos socioeconômicos da Fundação Norte-Mineira de Ensino Superior - FUNM. 
próprio mercado também é sempre restrito. $\mathrm{O}$ discurso implícito no trecho anterior mostra-se coerente com a tese de Cunha (1985, p. 52):

A imagem da escola é a de um mecanismo pelo qual os talentos inatos são transformados em habilitações cambiáveis, por sua vez, em renda, sob a forma de salário ou lucro. A sociedade aberta é aquela que permite aos indivíduos de cada qualidade/quantidade de talento atingirem o seu degrau. A sociedade brasileira, no seu estado atual, entretanto, não é ainda completamente aberta, pois há fatores que impedem a entrada (ou exigem a saída prematura) de muitos indivíduos da escola/escada antes de atingirem o "seu" degrau.

Tal visão parece, por sua vez, coerente com a noção de modernização conservadora, também discutida anteriormente, conforme Dulci (1999), já que, apesar de ter havido um ganho importante em virtude dos investimentos realizados na ampliação do sistema de ensino a partir da década de 1960 na região, tendo tido nesse processo a implantação do ensino superior um papel decisivo, como demonstrado, o acesso a tal ensino ainda permaneceu restrito a uma parcela mínima da população da região.

A FUNM, especialmente por meio da FAFIL, parece ter exercido, destarte, um papel importante no processo de expansão do sistema de ensino da cidade, principalmente de nível secundário. Quanto a essa expansão, a título de comparação, em palestra proferida pela professora Isabel Rebello de Paula, por ocasião da comemoração dos vinte anos de implantação do ensino superior regional, em 1982, coloca os seguintes dados:

[Dos] 57 ginásios existentes [no Norte de Minas], contamos hoje com cerca de 1446 estabelecimentos que oferecem ensino da $4^{a}$ à $8^{a}$ séries (antigo ginasial), dos quais, 1158 são municipais, 256 estaduais e apenas 22 particulares. Inverteu-se, finalmente, a participação do poder público na educação, rompendo-se assim com o círculo vicioso que a dominava. Não havia escolas porque não havia professores. ${ }^{9}$

\section{CONSIDERAÇÕES FINAIS}

Baseados nos documentos e publicações do período histórico analisado, pudemos encontrar discursos que se direcionavam, o mais das vezes, à necessária adaptação da região aos novos tempos de progresso, modernização e desenvolvimento, ocupando o sistema educacional um lugar de destaque nesse processo, tomada aqui uma noção de educação muito própria ao período analisado, ou seja, tanto de expansão de oportunidades de acesso à educação, inclusive superior, como

9 Documento encontrado no Centro de Pesquisa e Documentação Regional (CEPEDOR/ UNIMONTES). Texto datilografado, sem indicação de página, cujo título é Comemoração dos 20 anos do ensino superior regional, 1982. 
ao acesso a uma educação diferenciada, moderna, adaptada às novas exigências econômicas.

O ensino superior viria, portanto, lançar luz às problemáticas econômicas e sociais da região Norte de Minas, no intuito de sua adaptação e integração ao país em desenvolvimento, adaptação às novas formas capitalistas de organização do mercado. A implantação do ensino superior aparece como sinônimo de modernidade, haja vista não ser possível, dentro do discurso corrente na época, a um país ou região almejar desenvolvimento sem dispor de um sistema de educação escolar, em todos os seus níveis, conciso e adaptado aos novos tempos, condizente com os ideais produzidos pelos discursos desenvolvimentistas em nível nacional, com o intuito de capacitar a mão de obra necessária à industrialização da região e seu consequente desenvolvimento.

Assim, como a situação educacional da cidade e da região era deveras precária, a perspectiva do início de um processo de urbanização e modernização, que acabou efetivamente por mostrar-se intenso nas décadas posteriores, acabou por exigir a melhoria e a expansão do sistema de ensino, que, por sua vez, exigiu a necessidade da habilitação de um número maior de professores, principalmente de ensino secundário, que, por consequência, deu margem à implantação de cursos superiores que respondessem a tal demanda.

Parece que a relação modernidade-regionalismo também influenciou de maneira importante o processo de implantação do ensino superior na região, já que, ao mesmo tempo em que os discursos sustentavam-se na necessidade premente do desenvolvimento regional, o acesso ao ensino superior acabava por manter-se restrito a poucos, àqueles que já integravam a elite econômica e política local. Tal visão acaba por evidenciar uma noção de desenvolvimento limitado à sua dimensão econômica, em consonância com o modelo nacional desenvolvimentista brasileiro.

Faz-se necessário também considerar os reais impactos causados na região em virtude da implantação e expansão do ensino superior. É fato, portanto, que muito ainda há a se pesquisar no concernente ao ensino superior no Norte de Minas, sobretudo em relação ao papel que este ocupou em relação ao espaço de discussão e construção de conhecimentos relacionados ao desenvolvimento regional.

\section{REFERÊNCIAS}

Abreu, J. Educaşão, sociedade e desenvolvimento. Rio de Janeiro: Centro Brasileiro de Pesquisas Educacionais, 1968.

Aвreu, I. R. A influência das lideranças políticas no processo de criação das instituiçóes federais de ensino superior de Minas Gerais. 2006. Tese (Doutorado em História) - Faculdade de Filosofia e Ciências Humanas, Universidade Federal de Minas Gerais, Belo Horizonte, 2006. Beleza, O. Montes Claros em Foco, Montes Claros, 1962.

Brasil. Lei n. 4.323, de 11 de abril de 1964. Cria a Escola "Agrotécnica Antônio Versiani Athayde", no estado de Minas Gerais, e dá outras providências. Diário Oficial da União, Poder Executivo, Brasília, DF, 13 abr. 1964. Seção 1. p. 3.281.

Cunha, L. A. Educaşão e desenvolvimento social no Brasil. 8. ed. Rio de Janeiro: Francisco Alves Editora, 1985. 
Dulci, O. S. Política e recuperação econômica em Minas Gerais. Belo Horizonte: Ed. UFMG, 1999.

Fonseca, J. M. Montes Claros em Foco, Montes Claros, p. 35-36, ago. 1956.

Gazeta do Norte. Montes Claros, p. 1, 10 jan. 1960.

. Montes Claros, p. 1, 7 jan. 1960.

. Montes Claros, p. 2, 6 mar. 1960.

. Montes Claros, 29 jul. 1962.

IBGE - Instituto Brasileiro de Geografia e Estatística. Enciclopédia dos municípios brasileiros. 29 maio 1959. Planejada e orientada por Jurandyr Pires Ferreira. Rio de Janeiro, 1959. v. XXVI.

Maia, C. J.; Cordeiro, F. L. As faculdades da FUNM. In: Caleiro, R. C. L.; Pereira, L. M. (Org.). Unimontes: 40 anos de história. Montes Claros: Editora UNIMONTES, 2002.

MendonçA, A.W.P.C. et al. Pragmatismo e desenvolvimentismo no pensamento educacional brasileiro dos anos de 1950/1960. Revista Brasileira de Educação, Rio de Janeiro: ANPEd; Campinas: Autores Associados, v. 11, n. 31, p. 96-113, 2006.

Minas Gerais. Lei n. 2.615, de 24 de maio de 1962. Cria a Universidade Norte Mineira, e dá outras providências. Minas Gerais Diário do Executivo, Poder Executivo, Montes Claros, MG, 26 maio 1962.

Ministério da Educação e Cultura (MEC). [Carta] 18 de maio de 1959, Brasília, DF [para] Prefeitura Municipal de Montes Claros (PMMC), Montes Claros, MG, 01 folhas. Resposta à solicitação de incentivo à implantação do nível superior de ensino na região.

Montes Claros em Foco. Montes Claros: [s.n.], jun. 1957. Número Especial.

Montes Claros em Foco. Montes Claros: [s.n.], 1964.

Montes Claros: [s.n.], 1965.

Oliveira, M. F.M. Oprocesso de desenvolvimento de Montes Claros (MG), sob a orientação da SUDENE (1960-1980). 1996. Dissertação (Mestrado em História) - Faculdade de Filosofia, Letras e Ciências Humanas, Universidade de São Paulo, São Paulo, 1996.

Oliveira, M. F. M. O processo de formação de Montes Claros e da área mineira da SUDENE. In: ___; Rodrigues, L.(Org.). Formação social e econômica do Norte de Minas. Montes Claros: Editora UNIMONTES, 2000.

Pereira, A. M. Cidade média e região: o significado de Montes Claros no Norte de Minas. 2007. Tese (Doutorado em Geografia) - Programa de Pós-Graduação em Geografia da Universidade Federal de Uberlândia, Uberlândia, 2007.

Pereira, L. M. Em nome da região, a serviço do capital: o regionalismo político norte-mineiro. 2007. Tese (Doutorado em História Econômica) - Programa de Pós-Graduação em História Econômica da Faculdade de Filosofia, Letras e Ciências Humanas, Universidade de São Paulo, São Paulo, 2007.

Pinto, D. C. Campanha de aperfeiçoamento e difusão do ensino secundário: uma trajetória bem-sucedida? In: Congresso Brasileiro de História da Educação,1., 
2000, Rio de Janeiro. Anais... Rio de Janeiro, Sociedade Brasileira de História da Educação, 2000. Disponível em: <http://www.sbhe.org.br/novo/congressos/cbhe1/ anais/044_diana_couto.pdf $>$. Acesso em: 17 jan. 2010.

Raia, A. O que é a CADES? Gazeta do Norte, Montes Claros, p. 1., 10 jul. 1960.

ReIs, G. A construção de Brasília. Gazeta do Norte, Montes Claros, p. 1., 11 fev. 1960. Silveira, Y.O. Curso de suficiência. Gazeta do Norte, Montes Claros, p. 3, 10 jul. 1960. SouzA, J. V. A. Introdução à sociologia da educação. Belo Horizonte: Autêntica, 2007.

\section{SOBRE OS AUTORES}

CÉSAR Rota Júnior é doutorando em educação pela Universidade Federal de Minas Gerais (UFMG). Professor das Faculdades Integradas Pitágoras de Montes Claros (FIPMoc).

E-mail: cesarota@yahoo.com.br

Maria Helena de Souza Ide é doutora em educação pela Georg-August-Universität Göttingen (Alemanha). Professora na Universidade Estadual de Montes Claros (UNIMONTES).

E-mail: barbaraide@hotmail.com

Recebido em abril de 2013 Aprovado em dezembro de 2014 